\title{
O Uso da Tecnologia de Informação e Comunicação - TIC na Formação Inicial de Professores de uma Instituição de Ensino Superior no Município de Itaituba/Pará
}

\author{
Gilson Pedroso dos Santos ${ }^{1}$, Ana Paula Maffezzolli' ${ }^{1}$, Angel Pena Galvão ${ }^{1}$ \\ ${ }^{1}$ Universidade Federal do Oeste do Pará - UFOPA - Instituto de Ciências da Educação - \\ Programa de Pós-Graduação em Educação \\ gilsonpedrososantos@gmail.com, anaitb@gmail.com, mragalvao@gmail.com
}

\begin{abstract}
Resumo. O presente trabalho visa verificar se a formação inicial de professores, realizada numa instituição de ensino superior da cidade de Itaituba no estado do Pará, prepara os graduandos para a utilização de Tecnologias de Informação e Comunicação no processo de ensino e aprendizagem. A partir da aplicação de questionários aos alunos concluintes dos cursos de Letras e Pedagogia, constataram-se diversas dificuldades relacionadas ao uso das TIC's. Os resultados da pesquisa indicam que educar nos estabelecimentos de ensino da Amazônia, requer muita determinação e capacidade para superar obstáculos, porque são grandes os desafios que precisam ser superados para se ter uma educação de qualidade nessa região.
\end{abstract}

\begin{abstract}
The present study aims to verify if the initial teacher training, carried out in a higher education institution of the city of Itaituba in the state of Pará, prepares these students for the use of Information and Communication Technologies in the teaching and learning process. From the application of questionnaires to the graduating students of the letter and pedagogy courses, several difficulties related to the use of ICTs were verified. The research results indicate that educating in Amazonian educational institutions requires a lot of determination and ability to overcome obstacles, because the challenges that have to be overcome in order to have a quality education in this region are great.
\end{abstract}

\section{Introdução}

O presente trabalho apresenta resultados e análises de um levantamento de informação realizado junto a concluintes dos cursos de letras e pedagogia em Itaituba - PA, com o objetivo de verificar se a formação inicial prepara esses discentes para a utilização de Tecnologias de Informação e Comunicação no processo de ensino e aprendizagem.

O primeiro estabelecimento de ensino destinado à formação de professores teria sido instituído por São João Batista de La Salle em 1684, em Reims, com o nome de Seminário dos Mestres (DUARTE, 1986). Mas a questão da formação de professores exigiu uma resposta institucional apenas no século XIX, quando, após a Revolução Francesa, foi colocado o problema da instrução popular (SAVIANI, 2009). No Brasil a questão do preparo de professores emerge de forma explícita após a independência, quando se cogita da organização da instrução popular. A partir daí, examinando-se a questão pedagógica em articulação com as transformações que se processaram na sociedade brasileira ao longo dos últimos dois séculos (SAVIANI, 2009). 
Dessa forma, pode perceber a importância e a necessidade da formação de professores, sobre tudo a formação inicial, uma vez que esta influenciará significativamente a forma como o futuro professor exercerá sua profissão. Vale ressaltar também que a formação inicial de professores é um assunto que levanta bastantes discussões e não se pode negar a importância de uma formação de qualidade, de uma formação que possa preparar o professor para sua atuação em sala de aula, que o prepare para lidar com as adversidades e conflitos, além de capacitar estes graduandos para a utilização de tecnologias digitais no aprimoramento do processo de ensino e aprendizagem, sobretudo quando a região em questão é a Amazônia, um território bastante carente na economia, educação, políticas públicas, etc. Lima (2014) afirma que o enfrentamento da universalização da educação com qualidade na Amazônia por si só é uma tarefa de dimensões gigantescas. A opção pela adoção das TIC como fator central desse processo de universalização é ainda mais desafiador pela ausência de infraestrutura e pela inexistência de cultura de uso das tecnologias.

A educação sobre a Amazônia é deficiente no país e na própria região, principalmente em assuntos que ensinam a história, as tradições, os estilos de vida, os alimentos dos amazônidas, praticamente fazendo crer que esses brasileiros não existem. Se a Amazônia espera se desenvolver com base na floresta, o MEC e as secretarias estaduais de Educação precisam revisar as grades curriculares de primeiro grau à universidade para refletir a nova base da economia regional (CLEMENT, 2006).

A inovação tecnológica é inevitável e está presente nos mais diversos segmentos da sociedade, tendo reflexo direto na vida do ser humano, inclusive em sua formação acadêmica e profissional. Tendo em vista a grande influência da tecnologia na vida das pessoas e sua presença cada vez mais intensa nas salas de aula, cabe a adequada formação inicial do professor para que se adeque a essas mudanças e consiga integrar tecnologia, ensino e aprendizagem, uma vez que de acordo com Real, Tavares \& Dos Santos Picetti (2013, p. 664) "a tarefa de formar professores para utilizar as Tecnologias da Informação e da Comunicação, muitas vezes, não consegue preparar esses profissionais para o desafio que seu uso, em sala de aula, representa". Figueiredo, Nobre \& Passos (2015, p. 128) complementa que "o professor necessita dominar o conhecimento quanto às possibilidades de uso de recursos tecnológicos na educação, por meio de formação contínua no decorrer de toda sua carreira profissional."

Com o intuito de saber como se dá a aplicação de conhecimentos sobre TIC na formação inicial de professores, são apresentados os dados coletados com a pesquisa em campo, no qual foram aplicados, nos dias 21 e 22 de novembro de 2016, um questionário contendo 13 perguntas divididas em 05 questões objetivas e 08 subjetivas com 28 graduandos que estão cursando o oitavo semestre dos cursos de Licenciatura em Pedagogia e Licenciatura em Letras.

O trabalho está organizado nas seguintes partes: Introdução, onde são apresentados os objetivos do trabalho, relevância e tema; Tecnologia de Informação e Comunicação na Educação, onde se discorre sobre o papel das TIC na formação do professor; Métodos, onde se apresentam os procedimentos metodológicos dessa pesquisa; Resultados e Discussão, onde são apresentados e discutidos os resultados dessa investigação e Conclusões, onde são relacionados os resultados obtidos e os objetivos propostos do trabalho. 
VI Congresso Brasileiro de Informática na Educação (CBIE 2017)

Anais do XXIII Workshop de Informática na Escola (WIE 2017)

\section{Tecnologia da Informação e Comunicação na Educação}

As tecnologias evoluem de forma rápida e ocupam um papel de destaque exigindo das instituições de ensino e dos educadores, urgência em se adequar ao uso de recursos tecnológicos nas práticas educativas. Para que isso aconteça, é preciso apresentar novas formas de adquirir conhecimentos e as instituições formadoras de docentes precisam agregar aos seus conteúdos curriculares a agregação das tecnologias no processo de ensino e aprendizagem.

Contudo, a preocupação com a formação dos professores para o uso das tecnologias na educação, faz com que se busque compreender o conceito de tecnologia. Aproveitando o conceito de Cysneiros (2000) que afirma que a tecnologia educacional deve envolver algum tipo de objeto material que seja utilizado em alguma prática educativa voltada para o processo de ensino e aprendizagem que permite a relação entre educador, aprendiz e tecnologia.

Portanto, a tecnologia educacional são todos os recursos que permite o enriquecimento na arte de ensinar. Santiago (2006) aborda que durante muitos anos o lápis, caderno, giz, quadro negro foram os principais instrumentos para o ensino, depois surgiu a televisão, posteriormente os computadores e se achava que isso iria alterar a prática pedagógica, porém, só foram agregados a sala de aula sem grandes modificações. O autor afirma ainda que as evoluções dos recursos tecnológicos que podem ser utilizados em sala de aula, requer novas estratégias, metodologias e atitudes que superem a aula tradicional.

A tecnologia não deve ser somente incorporada como um objeto, o professor deve estar preparado para saber utilizá-la, é importante refletir uma educação com tecnologia que possa ser oferecida com qualidade, e para que isso aconteça, o professor deve ser preparado desde a sua formação inicial. Cabe-se perguntar, como deve ser a preparação do professor que deve estar preparado para as evoluções e inserção dos recursos tecnológicos em sala de aula? Motivação é o primeiro passo, segundo Cantini (2006), o professor deve reconhecer que é preciso mudar, acrescenta ainda que essa motivação deveria vir das instituições de ensino que devem proporcionar meios para o desenvolvimento profissional do docente, dando assim, oportunidade para que busque novos conhecimentos e novas técnicas de ensino.

Ainda segundo os autores, as instituições investem nos recursos materiais como o espaço físico para laboratórios de informática, TVs, vídeos, DVDs, computadores, dentre outros e não investem na formação continuada do professor. Frente ao desafio quanto ao uso de tecnologias e o receio de estar perdendo espaço para as máquinas, os autores afirmam que os professores estagnam e não buscam se atualizar e com isso todo o investimento em infraestrutura tecnológica que a instituição faz acaba sendo um desperdício, uma vez que não serão utilizadas para potencializar a aprendizagem do aluno e nem para melhorar a qualidade do desempenho profissional.

Contudo, são muitas as formas de utilização de recursos tecnológicos em sala de aula como, por exemplo, usando computador, tablet ou até mesmo o celular, pode se utilizar softwares para edição de texto, planilhas para realização de cálculos, aplicativos com fins específicos para o aluno aprender brincando, jogos educacionais e simulações, 
internet, chats ou sala de bate papo, e-mails, redes sociais, o uso de quadros digitais/interativos, de datashow, são alguns dos exemplos que o professor pode apropriar-se para aprimorar seu desempenho profissional e potencializar o processo de aprendizado do aluno.

É importante frisar que, o professor em sua formação, deve ser preparado e estimulado a apropriar-se de recursos tecnológicos para aprimorar suas aulas, deve entender porque está utilizando o recurso, como ele pode aliar um determinado recurso com o conteúdo disciplinar sem que a ferramenta tecnológica que está utilizando seja somente um objeto inserido nas suas aulas mantendo um ensino tradicional. As instituições de ensino superior devem inserir em seu Projeto Pedagógico do Curso, componente curricular que busque preparar esse professor que está sendo formado a utilizar as tecnologias de forma correta.

Partindo dessa premissa, buscou-se investigar se, em uma instituição de Ensino Superior localizada no município de Itaituba estado do Pará, o processo de formação do professor é assistido a utilização de tecnologias em sala de aula.

\section{Métodos}

Para o desenvolvimento deste, foi realizada pesquisa bibliográfica, tendo como palavras chaves Educação, Amazônia, Formação Inicial de Professores, Tecnologias Digitais e TIC's. Em seguida foi elaborado um questionário com questões que possibilitasse fazer um diagnóstico sobre a relação TIC's e Formação Inicial de Professores. Nos dias 21 e 22 de novembro de 2016, foi aplicado um questionário contendo 13 perguntas das quais 05 são objetivas e 08 são subjetivas com 38 acadêmicos que cursam o $8^{\circ}$ período do curso de Licenciaturas, sendo 10 graduandos do curso de licenciatura em Letras que possui atualmente 27 alunos matriculados e 28 graduandos do curso de Licenciatura em Pedagogia que possui 36 alunos matriculados.

As questões foram aplicadas com alunos do $8^{\circ}$ período por já estarem em fase de conclusão do curso e assim, pode-se obter dados mais contundentes para atingir o objetivo proposto. A idade média dos graduandos que responderam a pesquisa está entre 20 e 40 anos com predominância para as pessoas com idade entre 20 e 28 anos de idade. Após a aplicação do questionário, os dados foram organizados para que se pudesse analisar os resultados obtidos.

Buscou-se também analisar o Projeto Político Pedagógico dos curso de Pedagogia e Letras, e quais os recursos digitais que a IES disponibiliza para utilização dos alunos e professores. Foi analisado também, no que tange os componentes curriculares, quais disciplinas abordam sobre o uso de tecnologias no processo de ensino e aprendizagem.

\section{Resultados e Discussão}

Essa investigação tem como objetivo, verificar se na formação inicial de professores, estes são preparados para a utilização de Tecnologias de Informação e Comunicação em sala de aula. Foi escolhida uma faculdade privada localizada no município de Itaituba. A instituição está no mercado a 14 anos e oferta vários cursos de graduação, dentre eles os cursos de licenciaturas em Pedagogia e Letras, cursos que buscam formar profissionais na área da Educação. 
A Faculdade em questão, oferta diversos recursos tecnológicos para utilização tanto dos professores como dos acadêmicos. Além dos recursos tradicionais como quadro branco e TV, a IES possui também dois laboratórios de informática com 30 notebooks cada, datashow em todas as salas de aula, computadores na biblioteca, wifi gratuito e um quadro interativo. Analisando o PPC dos cursos, é visível a preocupação da IES quanto à disponibilização do acesso a esses recursos. Com relação aos componentes curriculares que contemplam a temática, observou-se que o curso de Pedagogia possui duas disciplinas voltadas para o uso de tecnologia na educação, uma chamada a Tecnologia da Informática e outra chamada Tecnologia no Processo Educacional onde as ementas contemplam conteúdo sobre o uso de tecnologias em sala de aula. Já no curso de Letras, possui uma disciplina chamada Informática e Educação.

Analisando os dados colhidos com a aplicação do questionário, pode-se definir que, com relação a área de atuação, 19 dos pesquisados atuam na área da educação, 06 atuam como auxiliar administrativo em empresas privadas, 02 são agentes de saúde municipal, 01 atua na área militar, 01 atua como vendedor e 09 estão sem empregos, somente estudam. Assim, percebe-se que dos 38 graduandos que cursam licenciatura, $50 \%$ atuam na área de educação.

Foi indagado qual o nível de conhecimento do graduando sobre informática e verificou-se que 21 dos graduandos afirmaram possuir conhecimento básico sobre informática, 2 possuem o nível intermediário e 15 responderam que possuem conhecimento avançado sobre informática. Contudo, pode-se considerar, no entanto, que todos possuem conhecimento sobre informática.

Também foram questionados se sabiam para que servem as Tecnologias de Informação e Comunicação, onde se pode verificar sobre o conhecimento de cada graduando com relação às Tecnologias de Informação e Comunicação, se sabem para que servem as TIC. Dos 38 alunos que responderam o questionário, 37 afirmam saber para que servem as TIC e 01 disse não saber para que serve.

Foi perguntado aos graduandos, se eles utilizam meios tecnológicos para desenvolver as atividades diárias, observou-se que 30 dos entrevistados afirmam que utilizam tecnologias nas suas atividades diárias. Elas afirmam utilizar computadores, notebooks, tablets, celulares, datashow, impressoras, TV, scanner e internet. Contudo, 08 pessoas afirmaram não utilizar de meios tecnológicos para execução de suas atividades diárias.

Questionou-se também, se durante o curso do ensino fundamental e médio, os professores utilizavam TIC nas aulas e verificou-se que 10 dos graduandos afirmaram que seus professores utilizavam TIC nas aulas. Quando solicitado para citar quais tecnologias utilizavam, as respostas foram: TV, Notebook e datashow. Também se pode verificar que 28 dos graduandos afirmam que os professores não utilizavam de meios tecnológicos digitais nas aulas quando cursava o ensino fundamental e médio.

$\mathrm{Na}$ pergunta de número 5 do questionário aplicado, foi questionado quais disciplinas da matriz curricular do curso contemplavam informações sobre as Tecnologias de Informação e Comunicação.

Foi verificado também que a grande parcela dos graduandos, no total de 27, afirmaram que a disciplina que contempla TIC para educação é a Informática Básica; 
Muitos dos entrevistados afirmaram que apesar do nome dessa disciplina se chamar desta forma, não fica claro quais tecnologias específicas para educação são trabalhadas nela, uma vez que as tecnologias citadas são muito genéricas.

Também foram coletadas informações quanto ao tipo de disciplina trabalhada, nesse caso se é de maneira teórica ou prática. 35 graduandos responderam que as disciplinas que abordam TIC são trabalhadas de maneira teórica e prática. Candau (1983) afirma a que teoria e prática são dois componentes indissolúveis da "práxis" definida como atividade teórico-prática, ou seja, tem um lado ideal, teórico e um lado material, propriamente prático, com a particularidade de que só artificialmente, por um processo de abstração, podemos separar um do outro. Essa relação não é direta nem imediata, fazendo-se através de um processo complexo, no qual algumas vezes se passa da prática à teoria e outras desta à prática. Portanto, é importante que os graduandos estudem através da mescla entre teoria e prática.

Analisou-se também, se durante o curso de graduação os graduandos são preparados quanto ao uso das TIC nas disciplinas e percebeu-se que a grande parcela dos graduandos, no total 24 afirmaram que o curso de formação inicial (graduação), não prepara o professor para usar com eficiência e bom desempenho as novas tecnologias. Isto também é comprovado em comentários dos graduandos afirmando que o professor da disciplina é despreparado e não sabe utilizar os recursos para ensinar, que possuem poucas aulas práticas e a carga horária da disciplina é pequena. Os resultados alinhamse com que os autores Freire e Prado (1996), falam sobre a importância do professor possuir o domínio das TICs, para depois ensinar, evidenciando a importância da capacitação e formação de professores, principalmente no que se trata do uso adequado das tecnologias em sala de aula.

Além disso, observou-se nas respostas, a forma pela qual os graduandos na sua formação inicial são preparados para utilizar as Tecnologias de Informação e Comunicação. Dezessete entrevistados responderam que lhes são repassadas informações referentes à Tecnologia básica (Word, Windows, Excel, Power Point). Onze entrevistados responderam que foram lhes repassadas informações relacionadas ao uso do computador como instrumento de auxílio no processo de ensino e aprendizagem. Dez responderam não serem capacitados para trabalhar as TIC com os alunos.

Foi indagado também sobre como os graduandos avaliam a importância das Tecnologias de Informação e Comunicação no processo de ensino e aprendizagem. Obteve-se como resultado: a) Dez afirmaram que é de suma importância para ajudar no processo de ensino aprendizagem pois pode proporcionar aulas diferenciadas, criativas e proveitosas. b) Onze responderam de forma generalizada que é importante e que precisam se aprofundar mais no assunto. c) Dez afirmaram ser importante para a realização de pesquisas e d) Sete pessoas não responderam.

Questionou-se por fim se os graduandos pretendem utilizar as Tecnologias de Informação e Comunicação nas suas aulas e de que forma. Obteve-se como resultado: a) Três pessoas não responderam; b) Doze apenas afirmaram que sim, todavia não especificaram de que forma; c) Treze afirmaram que pretendem utilizar datashow para apresentar slides, TV, computadores para realização de pesquisas; d) um dos graduandos informou que atua na zona rural, não tem infraestrutura para utilizar tecnologias, apesar de ter vontade; e) um utiliza TV para passar filmes, datashow para 
apresentar slides, palestras sobre tecnologias; f) um faz uso do celular para realização de pesquisas; g) um faz uso de vídeos e músicas; i) Três informaram que pretendem usar todos os recursos disponíveis e possíveis para ajudar no processo de ensino dos alunos. j) Dois fazem uso de vídeo aulas; k) Uma pessoa informou que pretende fazer uso de computador, datashow e aplicativos.

Dessa forma, pode-se afirmar que a tecnologia, na atualidade, é imprescindível para o funcionamento das instituições favorecendo o aprimoramento nos processos de comunicação, causando mudança estrutural na sociedade, no comportamento das pessoas e no modo de conceber o conhecimento. Com tanta evolução tecnológica e digital, as escolas também sofrem grandes influências no cotidiano, tendo que agregar computadores, datashow, celulares, softwares e outras tecnologias no seu processo de ensino e aprendizagem.

Muitos autores concordam com uso de tecnologias em sala de aula e afirmam ser importante, porém, para que isso ocorra, é necessário que a escola e os professores estejam preparados para lidar com os recursos tecnológicos.

Valente (1999, p. 2) apresenta o computador como meio para transmitir a informação ao aluno mantendo a prática pedagógica vigente. Portanto, a máquina foi usada para informatizar os processos de ensino existentes. Acrescenta o autor que, o preparo do cidadão para enfrentar essas mudanças é questionável.

Verificou-se, no entanto, que a tecnologia na educação, envolve novas formas de ensinar e de aprender, e que, portanto, a preocupação com a utilização correta das tecnologias que podem ser utilizadas em sala de aula não é recente. No cotidiano educacional, a tecnologia está cada vez mais presente seja levada pelo aluno, fornecida pela escola ou mesmo pelo professor, e são muitos os questionamentos quanto ao preparo dos professores para a utilização dos meios tecnológicos para a construção do conhecimento.

A formação desse professor não está em somente saber utilizar o computador, Sousa, Moita e Carvalho (2011, p. 21) afirmam que: "As escolas precisam se reinventar para sobreviver como instituição educacional. É importante que o professor aproveite os saberes advindos com a presença das tecnologias digitais da informação e da comunicação para que estes possam ser aplicadas em sua prática pedagógica."

A aplicação e mediação que o professor faz em sua prática pedagógica utilizando computador e as ferramentas multimídias em sala de aula, dependem, em parte, de como ele entende esse processo de transformação e de como se sente em relação a isso, se ele vê todo esse processo como algo benéfico, que pode ser favorável ao seu trabalho, ou se sente ameaçado e acuado por essas mudanças.

De Almeida (2009, p. 8) faz reflexões sobre como as Tecnologias de Informação e Comunicação - TIC vêm sendo apropriadas pela educação, como muitas escolas, políticas públicas e ações do governo idealizam o uso dessas tecnologias no processo de ensino e aprendizagem. Ainda de acordo com De Almeida $(2009$, p. 8), a facilidade em adquirir e usar os aparelhos tecnológicos faz com que cada vez mais empresas, governo, escolas e famílias os utilizem e muitas vezes esses recursos são empregados de forma que possam diminuir as dificuldades encontradas na educação e existe a ausência de 
políticas e ações governamentais que garantam a qualidade no ensino das escolas públicas.

São diversos os aparelhos tecnológicos que estão cada vez mais frequentes no cotidiano das pessoas, sejam computadores, celulares, câmeras, TV, filmadoras ou qualquer outro aparelho tecnológico, estão presentes no dia a dia, tanto em casa como no trabalho e na escola.

O problema está em como utilizar tais tecnologias para o aperfeiçoamento do processo pedagógico. Contudo, é importante que os professores estejam preparados para utilizar as tecnologias existentes, uma vez que elas estão cada vez mais frequentes no dia a dia dos alunos. Tais tecnologias podem ser usadas de forma eficiente, como aliados ao processo de ensino e aprendizagem de qualidade.

Tajra (2008, p. 189) contribui afirmando que as tecnologias são recursos que as escolas podem utilizar a seu favor. Novas formas de aprender são estimuladas através dos computadores, utilizando recursos como softwares de exercitação e simulação, jogos, fóruns digitais, www, dentre outros. Contudo, o que geralmente é visto em sala de aula são a utilização de datashow para apresentação de slides, a TV para apresentação de filmes, sabendo que as tecnologias que podem ser utilizadas em sala de aula não se limitam somente a essas citadas.

\section{Conclusões}

Pode se concluir através desse estudo a necessidade dos cursos de ensino superior em contemplar nas suas grades curriculares disciplinas relacionadas as tecnologias digitais, além da melhor preparação dos professores, que ministram aulas nesses cursos, em relação ao uso das tecnologias. A região, devido suas peculiaridades, não possui infraestrutura satisfatória para o uso das tecnologias, como internet a custos elevados e de qualidade precária, recursos tecnológicos mais caros que em outras partes do país, dentre outros problemas. Todavia, é necessária a discussão na formação inicial de como esses profissionais podem utilizar esses recursos para fins educacionais.

Além disso, quando se propõe aliar educação e tecnologia tendo como plano de fundo a Amazônia, pode-se destacar diversos desafios, tais como: dificuldades de acesso a internet, exclusão digital, escolas sem laboratórios de informática, profissionais sem conhecimento e habilidades referentes ao uso das tecnologias, dentre outros. A educação é um processo tão necessário à formação do indivíduo para sua vida em sociedade e para o exercício da sua cidadania. Quanto a educação na Amazônia, com todas as peculiaridades que essa região apresenta, pode-se perceber que é necessário se refletir profundamente sobre esse tema a fim de se tentar sugerir meios para se superar diversos desafios que essa região possui.

Essa investigação foi importante devido a necessidade de se diagnosticar como ocorre a formação inicial de professores em instituições de ensino na Amazônia, sobretudo nos municípios localizados dos grandes centros urbanos como Belém e Manaus. Face a esse diagnóstico é importante refletir sobre as dificuldades apresentadas. Por exemplo, constatou-se nesse trabalho como a necessidade de se melhorar a forma como os futuros educadores devem se apropriar dos recursos tecnológicos e, como as instituições de ensino superior devem se preparar para oferecerem em seus cursos, uma abordagem mais significativa das TICS, para que seus 
VI Congresso Brasileiro de Informática na Educação (CBIE 2017)

Anais do XXIII Workshop de Informática na Escola (WIE 2017)

alunos quando se tornarem professores, possam utilizá-las de modo satisfatório no processo de ensino e aprendizagem.

As TIC apresentam enorme potencial como ferramentas de auxílio no processo de ensino-aprendizagem, trazendo diversos benefícios para os alunos, escola e para os professores. Devido a essa importância, torna-se necessário a discussão e reflexão do uso das TIC desde a formação inicial dos professores, uma vez que estes são profissionais essenciais na consolidação da apropriação dessas tecnologias pela escola.

Como trabalhos futuros sugere-se a investigação de como as TICS podem ser utilizadas na formação continuada de professores e também na formação inicial, buscando propor discussões que possam contribuir para a formação desses profissionais e também na melhoria do processo de ensino e aprendizagem.

Dessa forma, propõe usar as tecnologias na sala de aula, porque embora exista muitas dificuldades relacionadas ao uso das tecnologias, estas podem sim auxiliar e enriquecer o processo de ensino e aprendizagem, porque o mundo contemporâneo exige uma conscientização por parte dos educadores acerca da dinâmica tecnológica, do potencial das Tecnologias Digitais, do reconhecimento do enorme e crescente volume de conteúdos, e da acelerada mudança de comportamento (cibercultura), elementos que se refletem fortemente no ambiente escolar (Zednik et al, 2014). Para tanto, cabe ao educador, a comunidade escolar, aos governantes discutirem formas de se superar esses desafios.

\section{Referências}

De Almeida, D. A. (2009). "TIC e educação no Brasil: breve histórico e possibilidades atuais de apropriação”, Pró-discente, 15(2).

Candau, V. M., \& Lelis, I. A. (1983). "A relação teoria-prática na formação do educador", Rumo a uma nova didática, 10, 56-72.

Cantini, Marcos Cesar, et al. O desafio do professor frente as novas tecnologias. Anais Educere, 2006, PUC/PR.

Clement, C. R., \& Higuchi, N. (2006). "A floresta amazônica e o futuro do Brasil", Ciência e Cultura, 58(3), 44-49.

Cysneiros, Paulo G. Novas tecnologias no cotidiano da escola. In: $23^{a}$ Reunião Anual da ANPEd, 2000, Caxambu. Anais $23^{\mathrm{a}}$ Reunião Anual da ANPEd. Caxambu: ANPEd, 2000.

Duarte, S. G. (1986). Dicionário brasileiro de educação. Antares.

Figueiredo, G., Nobre, I., \& Passos, M. L. S. (2015, October). "Tecnologias computacionais na educaçao: Desafios na prática docente", In Anais do Workshop de Informática na Escola (Vol. 21, No. 1, p. 127).

Freire, F. M., \& Prado, M. E. B. B. (1996). "Professores construcionistas: a formação em serviço", In Actas do III Congresso Ibero-Americano de Informática Educativa. 
VI Congresso Brasileiro de Informática na Educação (CBIE 2017)

Anais do XXIII Workshop de Informática na Escola (WIE 2017)

Lima, P. H. (2014). "PROFORMAR: Tecnologia e Educação para transformar a Amazônia", Revista EM FOCO - Fundação Esperança/IESPES, [S.1.], v. 1, n. 22, p. 62-68.

Real, L. M. C., Tavares, M. N. R., \& dos Santos Picetti, J. (2013). "Formação de Professores para o Uso Educacional de Tablets no Ensino Médio: possíveis mudanças na prática pedagógica", In Anais dos Workshops do Congresso Brasileiro de Informática na Educação (Vol. 2, No. 1).

Saviani, D. (2009). "Formação de professores: aspectos históricos e teóricos do problema no contexto brasileiro", Revista brasileira de educação.

Santiago, Dalva Gonzales. Novas Tecnologias e o Ensino Superior: Repensando a formação docente. Dissertação de Pós Graduação em Educação da PUC:Campinas, 2006.

Sousa, R. P. D., Moita, F. D., \& Carvalho, A. B. G. (2011). "Tecnologias digitais na educação."

Tajra, S. F. (2008). "Informática na educação: novas ferramentas para o professor na atualidade", rev. e ampl. São Paulo: Érica.

Valente, J. A. (1999). "O computador na sociedade do conhecimento", Campinas: Unicamp/NIED, 11-18.

Zednik, H., Tarouco, L. M., Klering, L., García-Valcárcel, A., \& Guerra, E. P. (2014). "Tecnologias Digitais na Educação: proposta taxonômica para apoio à integração da tecnologia em sala de aula", In Anais do Workshop de Informática na Escola (Vol. 20, No. 1, p. 507). 